\title{
Severe pancytopenia as presenting feature in newly diagnosed multiple myeloma (NDMM): a rare presentation
}

\author{
C. De Vriendt ${ }^{1}$, S. Kennes ${ }^{1}$, M. Hofmans ${ }^{2}$, P. Vlummens ${ }^{1}$ \\ Department of Hematology ${ }^{1}$, Clinical Biology ${ }^{2}$, Ghent University Hospital, Ghent, Belgium.
}

\section{INTRODUCTION}

Multiple myeloma (MM) accounts for $10 \%$ of all haematological malignancies with an incidence in Europe of 4.5-6.0/100 000/year [1]. The International Myeloma Working Group criteria are used for establishing the diagnosis of multiple myeloma, including signs of end-organ damage such as hypercalcaemia, renal insufficiency, anaemia or bone lesions [2]. In contrast to anemia, pancytopenia as initial presentation of this disease is an uncommon finding.

\section{OBJECTIVES}

Illustrated by an intriguing presentation mimicking an acute leukemia, we want to expand insights into the clinical spectrum of NDMM. We try to validate the scarcity of this pancytopenia at diagnosis by analyzing our cohort of 172 NDMM patients.

\section{METHODS}

We identified a patient who presented with severe pancytopenia and febrile neutropenia as the only sign of NDMM. As this was an extremely atypical presentation, we performed a retrospective analysis of all NDMM patients seen at our center between 01/01/2009 and 31/07/2017 to identify additional cases. All 172 patients met the IMWG diagnostic criteria for MM.

\section{CASE PRESENTATION}

A 66-year-old female was referred because of febrile neutropenia. She had developed progressive dyspnea over the last few weeks and spiking fever since 96 hours. Laboratory work-up performed by the general physician showed severe pancytopenia with $\mathrm{Hg} 4 \mathrm{~g} / \mathrm{dL}$, WBC 600/ $\mu \mathrm{L}$ and thrombocytes $27000 / \mu \mathrm{L}$. No peripheral blasts, nor plasmacells were seen (Table 1). Due to the acute onset and severity of the cytopenia, an acute leukemia with concomitant infection was suspected.

\section{Table 1: Laboratory values at diagnosis}

\begin{tabular}{|c|c|c|c|}
\hline & Value & Unit & References \\
\hline Hemoglobin & 4.0 & $\mathbf{q} / \mathbf{d l}$ & $11.8-14.8$ \\
\hline Hematocrit & 12.0 & $\%$ & 35.8-43.7 \\
\hline MCV & 109.1 & $\mathrm{fL}$ & 82.3-96.4 \\
\hline Platelets & 51 & $10 \mathrm{E} 3 / \mu \mathrm{L}$ & $171-374$ \\
\hline White blood cells & 0.46 & $10 \mathrm{E} 3 / \mu \mathrm{L}$ & $3.65-9.30$ \\
\hline \multicolumn{4}{|c|}{ Microscopical differentiation } \\
\hline Neutrophils & 339 & $/ \mu \mathrm{L}$ & $1573-6100$ \\
\hline Lymphocytes & 115 & $/ \mu \mathrm{L}$ & 1133-3105 \\
\hline Monocytes & 6 & $/ \mu \mathrm{L}$ & $247-757$ \\
\hline Eosinophils & 0 & $/ \mu \mathrm{L}$ & $28-273$ \\
\hline Basophils & 0 & $/ \mu \mathrm{L}$ & $6-50$ \\
\hline Total Bilirubine & 0.5 & $\mathrm{mg} / \mathrm{dL}$ & $0.2-1.1$ \\
\hline Schistocytes & 0 & $/ 1000$ & \\
\hline Creatinine & 0.87 & $\mathrm{mg} / \mathrm{dL}$ & $0.55-0.96$ \\
\hline Total protein & 79 & g/L & \\
\hline LDH (IFCC) & 269 & $\mathrm{U} / \mathrm{L}$ & $105-233$ \\
\hline Ferritine & 1638 & $\mu \mathrm{g} / \mathrm{L}$ & $25-250$ \\
\hline Vitamine B12 & 337 & $\mathrm{ng} / \mathrm{L}$ & $197-866$ \\
\hline Folic acid & 6.2 & $\mu \mathrm{g} / \mathrm{L}$ & $1.8-9.0$ \\
\hline C-reactive proteine & 141.9 & $\mathrm{mg} / \mathrm{L}$ & $<5.0$ \\
\hline
\end{tabular}

Subsequent bone marrow biopsy surprisingly revealed the presence of atypical plasmacells (>60\%, CD138+/kappa+, picture 1). Serum protein electrophoresis (SPEP) displayed the presence of an $\operatorname{lgG} \mathrm{M}$-component of $31.4 \mathrm{~g} / \mathrm{L}$ and there was skewing of the FLC (free light chain) ratio with Kappa preponderance.
As such, the diagnosis of NDMM was made. Molecular karyotype and FISH analysis showed no aberrations. Urine analysis demonstrated Bence Jones proteinuria.

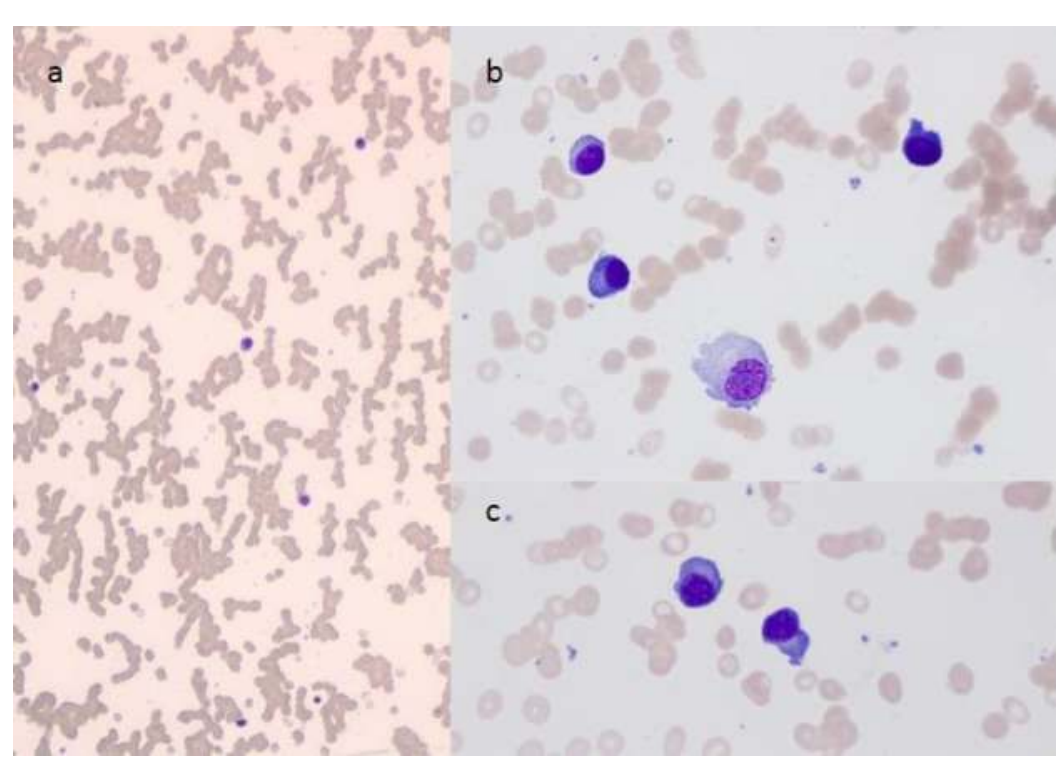

Picture 1: (a) Bone marrow aspirate showing poor cellularity and marked rouleau formation (May-Grunwald-Giemsa staining, 100x). (b and c) Monoclonal plasma cells with atypical and pleomorphic features: presence of nucleoli, loss of perinuclear hof and multinucleated forms (May-Grunwald-Giemsa staining, 100x).

\section{RESULTS}

Retrospective analysis of our patient cohort confirmed the rarity of this presentation as no other patient had pancytopenia as initial key feature. Also, no one had ever presented with grade III/IV thrombocytopenia/neutropenia, respectively. Although 2 additional patients $(\mathrm{N}=3 / 173,3.4 \%)$ had a $\mathrm{Hg}<7 \mathrm{~g} / \mathrm{dL}$ at time of diagnosis, none had such a marked pancytopenia as seen in this patient $(\mathrm{N}=1 / 173,0.5 \%)$.

\section{DISCUSSION}

Our incidence of $0,5 \%$ is lower than expected from a retrospective study conducted by Subramanian et al. where $9 \%$ of the NDMM patients presented themselves with pancytopenia [3]. On the other hand, Sridevi HB et al. validates the rarity of this presentation in their retrospective cohort study by calling pancytopenia in NDMM likewise an enigma [4].

\section{CONCLUSION}

Albeit rare, pancytopenia can be the presenting feature of NDMM as seen in our case report and cohort analysis. Its presence therefore doesn't exclude the possibility of MM. Pancytopenia without peripheral circulating blasts should always raise suspicion for the diagnosis of MM in order to avoid delay of treatment. Ordering a SPEP and serum FLC measurement in case of a pancytopenia without blasts is never exorbitant.

\section{REFERENCES}

[1] Palumbo A, Bringhen S, Ludwig $\mathrm{H}$ et al. Personalized therapy in multiple myeloma according to patient age and vulnerability: a report of the European Myeloma Network (EMN). Blood 2011; 118: 4519-4529.

[2] Rajkumar SV, Dimopoulos MA, Palumbo A et al. International Myeloma Working Group Updated Criteria for the Diagnosis of Multiple Myeloma. Lancet Oncol. 2014;15:e538-e548.

[3] Subramanian R, Basu D, Dutta TK. Prognostic significance of bone marrow histology in multiple myeloma. Indian J Cancer. 2009;46:40-45.

[4] Sridevi HB, Rai S, Suresh PK, Somesh MS, Minal J. Pancytopenia in Multiple Myeloma- An Enigma: Our Experience from Tertiary Care Hospital. Journal of Clinical and Diagnostic Research: JCDR. 2015;9(11):EC04-EC06. doi:10.7860/JCDR/2015/12788.6718 